\title{
Effects of Monster Energy Drink on Cardiovascular and Renal Functioning Young Adults
}

\author{
Ted Wilson*, Dustin L. Denzer, Frances R. Ragsdale \\ Department of Biology, Winona State University, Winona, MN 55987 USA
}

"Corresponding author: Ted Wilson, Department of Biology, 232 Pasteur Hall, Winona State University, Winona, MN 55987, Tel: 507-457-2485; E-mail: twilson@winona.edu

\begin{abstract}
Energy drink consumption is popular among the college-aged population for perceived improvements in mental function and alertness, but anecdotally linked to cardiovascular dysfunction. Fasting $19.4 \pm 1.03$ year old subjects $(n=75)$ consumed $480 \mathrm{ml}$ of Monster Energy drink, isocaloric dextrose, water, or nothing. Blood glucose increased significantly after Monster Energy drink and isocaloric dextrose at $30 \mathrm{~min}$. Urine formation was significantly greater at 120 minutes in the Monster Energy drink group. In the present study consumption of Monster Energy drink was associated with no deleterious changes in cardiovascular or renal physiology.
\end{abstract}

Received Date: January 17, 2016

Accepted Date: September 06, 2016

Published Date: September 12, 2016

Citation: Wilson, T., et al. Effects of Monster Energy Drink on Cardiovascular and Renal Functioning Young Adults. (2016) Int J Food Nutr Sci 3(2): 350-353.

DOI: $10.15436 / 2377-0619.16 .046$

Keywords: Energy drink; Cardiovascular dysfunction; Caffeine; B-vitamin; Taurine; Glycemic response

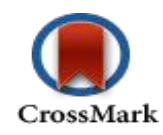

\section{Introduction}

Energy drinks are marketed to young people promising many things including increased energy, enhanced physical performance, and improved alertness. Monster was the \#2 top selling energy drink in the United States and had projected earnings worth $\$ 3.1$ billion dollars in the first half of $2013^{[1]}$. Sales of all energy drinks were up between $14-21 \%$ in $2012^{[2]}$ and $6.7 \%$ in 2013 , which contrasts with a relatively stagnant soda market ${ }^{[1]}$.

However, energy drinks have been anecdotally linked to deleterious health problems, especially in young persons. Energy drink consumption is also predictive of the development of problem behavioural syndrome in this population $^{[3]}$. A review of information from the US National Poison Data System and found that only $0.2 \%$ of all calls (over 2.3 million in total) were related to EDs including the effects of EDs plus additional additives (alcohol); of these inquiries, only a very small portion were for EDs alone ${ }^{[4]}$. Most of the reports were for abuse of EDs by male children and were nonfatal ${ }^{[5]}$.

Goldfarb et al, 2014 ${ }^{[6]}$ observed that cardiovascular conditions may also be related to energy drink consumption that include a trial fibrillation, reverse takotsubo cardiomyopathy, supraventricular tachycardia, spontaneous coronary artery dissection, and hypertension; nine fatalities were attributed to acute ED abuse with or without alcohol or other additives. Of the psychiatric conditions, all appeared to be exacerbations of sleeplessness, medication withdrawal, or blatant ED abuse.

The primary active ingredient in most energy drinks may be caffeine $(50-505 \mathrm{mg} / \text { serving })^{[7]}$, however B-vitamins, taurine, guarana, and ginseng could also influence physiology and mental function. Taurine has been specifically linked to non-deleterious changes in cardiac function in previous studies ${ }^{[8,9]}$. In our previous investigation, $250 \mathrm{ml}$ of Red Bull was associated with few statistically significant changes in cardiovascular physiology, electrocardiographic measurements, or urinary chemistries, none being deleterious ${ }^{[10]}$, a similar result also observed by others ${ }^{[11]}$. While Red Bull has been examined in previous studies, descriptions of the clinical effects of consuming Monster, the \#2 energy drink in the US have not been completed and needed to expand our understanding of these beverages.

Energy drink packaging has evolved towards extremes from two fluid ounce energy "shots" to larger 16 to 32 fluid 
ounce containers. Energy drinks are frequently consumed to completion at a single sitting even when packaging dictates it contains multiple servings. The effects of consuming more than a single serving of energy drink have not been characterized in the literature. The present study explored whether consumption of a larger $16 \mathrm{fl} \mathrm{oz}(480 \mathrm{ml})$ can of Monster Energy Drink ${ }^{\circledR}$ containing two suggested servings by fasting college-aged subjects could alter their glycemic response, cardiovascular function, urinary physiology, and visual reflex time.

\section{Materials and Methods}

Following Winona State University Institutional Review Board approval, informed consent was obtained prior to volunteer participation. Healthy participants (52 female, 23 male; $19.4 \pm 1.03$ years old; $71.9 \pm 15.4 \mathrm{~kg}$; and $66.9 \pm 4.23 \mathrm{~cm}$ ) were recruited for this trial that excluded persons with diabetes, heart disease, mental health problems or depression, kidney disease, or liver disease. Subjects reported to the laboratory following a 12-hour fast from all food or beverages (including alcohol) that included a ban on exercise for 6 hours prior to arrival in the laboratory. Subjects were randomized to receive one of four treatments consisting of Monster Energy Drink (full can; 200 Calories; $16 \mathrm{floz} ; 480 \mathrm{ml})$, isocaloric dextrose $(480 \mathrm{ml})$, water $(480 \mathrm{ml})$, or a no-beverage control. After a 15 minute waiting period in the lab, baseline cardiac, reaction time, hematocrit and blood glucose values were obtained (0-minutes). After which treatment beverages were administered and consumed to completion within 4 minutes of initiation. The $480 \mathrm{ml}$ serving of Monster Energy drink contained $200 \mathrm{Cal}$ (27 g sugars), $3.4 \mathrm{mg}$ riboflavin, $40 \mathrm{mg}$ niacin, $4 \mathrm{mg}$ vitamin $\mathrm{B}_{6}, 12 \mu \mathrm{g}$ vitamin $\mathrm{B}_{12}$, $360 \mathrm{mg}$ sodium, $2 \mathrm{~g}$ taurine, $400 \mathrm{mg}$ panax ginseng and $5 \mathrm{~g}$ of a proprietary "energy blend" (L-carnitine, glucose, caffeine, quarana, inosotol, gluconolactone, and maltodextrin). The Monster Energy drink administered was part of a single manufactured lot. A finger pulse oximeter was used to measure heart rate and percent blood oxygen saturation $\left(\% \mathrm{SpO}_{2}\right)$. A lancet was used to collect blood samples from the finger. Comfort wave test strips and Accu-chek Advantage blood glucose meters (Roche Diagnostics, Indianapolis, IN) were used to measure blood glucose just prior to consumption (0-minutes) and then 30-, 60- and 120- minutes post-consumption ${ }^{[12]}$. Urine was collected by voiding into a collection container and analyzed at 0,60 , and 120 minutes for volume, specific gravity and urine formation rate. Visual reflex time was assessed at 0 and 60 minutes $^{[13]}$. Data are expressed as mean \pm standard deviation. After two-way ANOVA (treatment and time) significant differences $(\mathrm{p} \leq 0.05)$ were determined using multiple comparisons with Tukey-Kramer adjustment (SAS Inst. Inc., Cary, N.C., U.S.A.).

\section{Results and Discussion}

The college-aged subjects in this study consumed the entire $480 \mathrm{ml}$ serving of Monster Energy Drink, isocaloric sugar water, or water in a single sitting within 4 minutes. Blood glucose increased significantly with Monster energy drink and dextrose at $30 \mathrm{~min}$ and returned to baseline levels by $120 \mathrm{~min}-$ utes (Table 1). These results are similar to the peak glycemic response in college-aged subjects in response to a cranberry juice containing glycemic load and volume comparable to the energy $\operatorname{drink}^{[12]}$. The glycemic response observed in this study was also similar to that associated with soft drink consumption ${ }^{[14]}$.

Energy drinks can alter cardiovascular function in some persons ${ }^{[11]}$. This could alter regional perfusion and oxygenation within the brain, and has been suggested as a potential contributor to behavioral pathologies including attention deficient hyperactivity disorder ${ }^{[15]}$. Caffeine has the potential to alter cardiovascular function because it can modify cyclic AMP formation and degradation, and because it serves as a receptor agonist for adenosine receptors that can alter sympathetic activity either directly or indirectly. However, in the present study, the large 480 $\mathrm{ml}$ volume of energy drink administered still had no significant changes on heart rate, hematocrit, or $\% \mathrm{SpO}_{2}$ (Table 1). The lack of cardiovascular effects supports our previous findings ${ }^{[10]}$ and the findings of others for caffeine and taurine ${ }^{[8,16,17]}$. Reflex time improvements are central to the health claims of many energy drinks, although it was not found to be altered by treatments in the present investigation (Table 1).

Consumption of a large fluid volume can promote increased urine formation and the presence of caffeine also promotes diuresis ${ }^{[18]}$, of course the caffeine in Monster Energy drink is one of many other substances that could also alter urine formation. Urine formation rate and urine specific gravity were examined to examin to determine if the non-caloric contents of Monster Energy drink contributed significantly to the diuresis that was expected following the consumption of $480 \mathrm{ml}$ (Table 1). Changes in urine specific gravity remained constant at around $1.0 \pm 0.1 \mathrm{~g} / \mathrm{mL}$ for all groups at all times. While urine formation rate measurement was not attempted 30 minute post prandially. At 60 minutes urine formation rate for the isocaloric control group was $0.8 \pm 0.4 \mathrm{ml} /$ minute; the rate was larger within the Monster Energy Drink at $3.1 \pm 3.2 \mathrm{ml} /$ minute, therefore statistical significance was not achieved between the groups at 60 minutes, although the variability within ME consumers was 8 times greater. At 120 minutes the urine formation rate $(\mathrm{ml} /$ $\mathrm{min}$ ) in Monster Energy drink consumers was significantly higher $(p<0.05)$ relative to the other three groups, an effect that may have been due to the diuretic effect of caffeine ${ }^{[19]}$. This pilot trial was not designed to determine which Energy Drink chemical ingredient was most responsible for any physiological or reaction time effects, but to simple determine if effects could be observed. Future studies may seek to determine if the diuretic effect observed within the Monster Energy drink group were due to caffeine or the other contents using a principle component analysis or using each ingredient as a control group matched with isocaloric carbohydrate.

Energy drinks have been suggested to improve reaction time in some prior studies and in the present study consumption of Monster Energy drink was associated with a 14\% improvement in reflex reaction time, however the change was not statistically significant relative to the other treatment groups. 
Effects of Monster Energy Drink in Young Adults

Table 1: Effect of Monster Energy drink consumption on glycemic response, cardiovascular function, visual reflex time and renal function.

\begin{tabular}{|c|c|c|c|c|c|}
\hline \multicolumn{2}{|l|}{ Treatment } & 0 min & $30 \mathrm{~min}$ & $60 \mathrm{~min}$ & $120 \mathrm{~min}$ \\
\hline \multirow[t]{4}{*}{ Blood Glucose (mg/dL) } & ME* & $93.7 \pm 8.3^{\mathrm{A}, 1}$ & $142.0 \pm 27.7^{\mathrm{A}, 2}$ & $105.0 \pm 17.9^{\mathrm{A}, 1,2}$ & $93.6 \pm 12.4^{\mathrm{A}, 1,2}$ \\
\hline & ICSW** & $96.3 \pm 8.4^{\mathrm{A}, 1}$ & $145.0 \pm 35.9^{\mathrm{A}, 2}$ & $98.5 \pm 11.3^{\mathrm{A}, 1,2}$ & $90.5 \pm 11.7^{\mathrm{A}, 1}$ \\
\hline & Water & $97.1 \pm 9.9^{\mathrm{A}, 1}$ & $95.1 \pm 10.2^{\mathrm{B}, 2}$ & $97.0 \pm 15.2^{\mathrm{A}, 1}$ & $94.4 \pm 7.7^{\mathrm{A}, 1}$ \\
\hline & Nothing & $91.8 \pm 8.2^{\mathrm{A}, 1}$ & $91.7 \pm 9.8^{\mathrm{B}, 1}$ & $91.3 \pm 6.5^{\mathrm{A}, 1}$ & $91.3 \pm 7.6^{\mathrm{A}, 1}$ \\
\hline \multirow[t]{4}{*}{ Heart Rate (beat/min) } & ME & $86.1 \pm 13.4^{\mathrm{A}, 1}$ & $81.2 \pm 15.1^{\mathrm{A}, 1}$ & $80.2 \pm 14.2^{\mathrm{A}, 1}$ & $82.6 \pm 11.7^{\mathrm{A}, 1}$ \\
\hline & ICSW & $85.9 \pm 15.5^{\mathrm{A}, 1}$ & $80.2 \pm 16.7^{\mathrm{A}, 1}$ & $81.5 \pm 13.2^{\mathrm{A}, 1}$ & $76.9 \pm 12.4^{\mathrm{A}, 1}$ \\
\hline & Water & $93.4 \pm 12.9^{\mathrm{A}, 1}$ & $80.4 \pm 8.2^{\mathrm{A}, 1}$ & $87.8 \pm 11.9^{\mathrm{A}, 1}$ & $85.6 \pm 9.8^{\mathrm{A}, 1}$ \\
\hline & Nothing & $87.5 \pm 17.4^{\mathrm{A}, 1}$ & $85.2 \pm 14.3^{\mathrm{A}, 1}$ & $82.7 \pm 12.4^{\mathrm{A}, 1}$ & $83.7 \pm 10.8^{\mathrm{A}, 1}$ \\
\hline \multirow[t]{4}{*}{ Hematocrit (\%) } & ME & $44.7 \pm 4.9^{\mathrm{A}, 1}$ & $43.0 \pm 5.17^{\mathrm{A}, 1}$ & $43.6 \pm 4.5^{\mathrm{A}, 1}$ & $43.5 \pm 5.4^{\mathrm{A}, 1}$ \\
\hline & ICSW & $43.2 \pm 6.5^{\mathrm{A}, 1}$ & $41.4 \pm 3.3^{\mathrm{A}, 1}$ & $41.3 \pm 3.4^{\mathrm{A}, 1}$ & $41.8 \pm 3.3^{\mathrm{A}, 1}$ \\
\hline & Water & $43.9 \pm 6.9^{\mathrm{A}, 1}$ & $41.4 \pm 4.9^{\mathrm{A}, 1}$ & $42.1 \pm 5.4^{\mathrm{A}, 1}$ & $42.8 \pm 34.0^{\mathrm{A}, 1}$ \\
\hline & Nothing & $42.8 \pm 3 .^{A, 1}$ & $41.6 \pm 3.4^{\mathrm{A}, 1}$ & $43.4 \pm 4.6^{\mathrm{A}, 1}$ & $41.1 \pm 2.9^{\mathrm{A}, 1}$ \\
\hline \multirow[t]{4}{*}{$\% \mathrm{SpO}_{2}$} & ME & $97.8 \pm 1.4^{\mathrm{A}, 1}$ & $98.3 \pm 0.9^{\mathrm{A}, 1}$ & $97.6 \pm 1.3^{\mathrm{A}, 1}$ & $97.9 \pm 0.9^{\mathrm{A}, 1}$ \\
\hline & ICSW & $97.8 \pm 1.1^{\mathrm{A}, 1}$ & $98.1 \pm 1.0^{\mathrm{A}, 1}$ & $98.1 \pm 1.3^{\mathrm{A}, 1}$ & $97.9 \pm 1.1^{\mathrm{A}, 1}$ \\
\hline & Water & $97.3 \pm 1.2^{\mathrm{A}, 1}$ & $97.8 \pm 1.2^{\mathrm{A}, 1}$ & $97.8 \pm 1.0^{\mathrm{A}, 1}$ & $96.8 \pm 2.2^{\mathrm{A}, 1}$ \\
\hline & Nothing & $97.2 \pm 1.1^{\mathrm{A}, 1}$ & $97.7 \pm 1.0^{\mathrm{A}, 1}$ & $97.6 \pm 1.1^{\mathrm{A}, 1}$ & $97.5 \pm 1.4^{\mathrm{A}, 1}$ \\
\hline \multirow{4}{*}{$\begin{array}{l}\text { Visual } \\
\text { Reflex } \\
\text { Time } \\
\text { (sec) }\end{array}$} & ME & $0.29 \pm 0.10^{\mathrm{A}, 1}$ & - & $0.25 \pm 0.06^{\mathrm{A}, 1}$ & - \\
\hline & ICSW & $0.27 \pm 0.03^{\mathrm{A}, 1}$ & - & $0.26 \pm 0.03^{\mathrm{A}, 1}$ & - \\
\hline & Water & $0.30 \pm 0.08^{\mathrm{A}, 1}$ & - & $0.29 \pm 0.10^{\mathrm{A}, 1}$ & - \\
\hline & Nothing & $0.29 \pm 0.05^{\mathrm{A}, 1}$ & - & $0.29 \pm 0.10^{\mathrm{A}, 1}$ & - \\
\hline \multirow{4}{*}{$\begin{array}{l}\text { Urine } \\
\text { Formation } \\
\text { Rate } \\
\text { (ml/min) }\end{array}$} & ME & - & - & $3.1 \pm 3.2^{\mathrm{A}, 1}$ & $2.2 \pm 1.6^{\mathrm{A}, 1}$ \\
\hline & ICSW & - & - & $0.8 \pm 0.4^{\mathrm{A}, 1}$ & $1.0 \pm 0.8^{\mathrm{B}, 1}$ \\
\hline & Water & - & - & $1.6 \pm 1.3^{\mathrm{A}, 1}$ & $1.52 \pm 1.0^{\mathrm{B}, 1}$ \\
\hline & Nothing & - & - & $0.6 \pm 0.6^{\mathrm{A}, 1}$ & $0.3 \pm 0.3^{\mathrm{B}, 1}$ \\
\hline \multirow{4}{*}{$\begin{array}{l}\text { Urine } \\
\text { Specific } \\
\text { Gravity } \\
(\mathrm{g} / \mathrm{ml})\end{array}$} & ME & $1.0 \pm 0.1^{\mathrm{A}, 1}$ & - & $1.0 \pm 0.1^{\mathrm{A}, 1}$ & $1.0 \pm 0.1^{\mathrm{A}, 1}$ \\
\hline & ICSW & $1.0 \pm 0.1^{\mathrm{A}, 1}$ & - & $1.0 \pm 0.1^{\mathrm{A}, 1}$ & $1.02 \pm 0.1^{\mathrm{A}, 1}$ \\
\hline & Water & $1.0 \pm 0.1^{\mathrm{A}, 1}$ & - & $1.0 \pm 0.1^{\mathrm{A}, 1}$ & $1.0 \pm 0.1^{\mathrm{A}, 1}$ \\
\hline & Nothing & $1.0 \pm 0.1^{\mathrm{A}, 1}$ & - & $1.0 \pm 0.1^{\mathrm{A}, 1}$ & $1.02 \pm 0.1^{\mathrm{A}, 1}$ \\
\hline
\end{tabular}

*ME: Monster Energy Drink **ICSW: Isocaloric sugar water, Data $(\mathrm{n}=75)$ expressed as mean \pm standard deviation. Significant differences $(\mathrm{p}$ $\leq 0.05)$ between groups within time indicated by differing superscript letters. Significant differences $(\mathrm{p} \leq 0.05)$ between times within group are indicated by differing superscript numbers.

\section{Summary}

This study suggests that consumption of $16 \mathrm{oz}(480 \mathrm{ml})$ of Monster Energy Drink following an overnight fast is not associated with adverse cardiovascular or renal effects in healthy young college-aged students. This study confirms the previous observations of ourselve ${ }^{[10]}$ and others ${ }^{[11]}$ that experimental evidence to support the deleterious effects are lacking. A literature search using PubMed with the key words of "energy drink" yielded 204 citations (June 10, 2015) ${ }^{[20]}$. Of these, only 19 reports were found dealing with EDs alone and deleterious or fatal psychiatric, cardiovascular, or neurologic conditions. Among young adults, the incidence of sudden cardiac death following the consumption of EDs is very low. Even with EDs alone, naïve drinkers may experience traumatic consequences with excess consumption due to caffeine sensitivity. Of the 19 deleterious cases reported in the primary literature, of which there were nine fatalities, extenuating circumstances including excessive exercise and ED consumption or alcohol-ED ingestion triggered fatal cardiovascular events. Future studies may wish to repeat the study described here in persons known to be affected by attention deficient hyperactivity disorder because energy drink consumption in this population is predictive of problem behaviors.

Acknowledgements: The authors wish to acknowledge financial support from the Office of Academic Affairs and statistical support from Dr. Tisha Hooks and Christopher Malone, Department of Mathematics and Statistics, Winona State University. This study was not supported by any beverage or energy drink company. 


\section{References}

1) Kallmyer, T. Top selling energy drink brands. Accessed July (2014) Caffeine Informer.

2) Munarriz, R. Soda sales are slipping, but energy drinks are still buzzing. (2014) Daily Finance Investor Center.

3) Miller, K.E. Energy Drinks, Race, and Problem Behaviors Among College Students. (2008) J Adolesc Health 43(5): 490-497.

4) Seifert, S.M., Seifert, S.A., Schaechter, J.L., et al. An analysis of energy-drink toxicity in the National Poison Data System. (2013) Clin Toxicol (Phila) 51(7): 566-574.

5) Burrows, T., Pursey, K., Neve, M., et al. What are the health implications associated with the consumption of energy drinks? A systematic review. (2013) Nutr Rev 71(3): 135-148.

6) Goldfarb, M., Tellier, C., Thanassoulis, G. Review of published cases of adverse cardiovascular events after ingestion of energy drinks. (2014) Am J Cardiol 113(1): 168-172.

7) Reissig, C.J., Strain, E.C., Griffiths, R.R. Caffeinated energy drinks A growing problem. (2009) Drug Alcohol Depend 99(1-3): 1-10.

8) Baum, M., Weiss, M. The influence of taurine containing drink on cardiac parameters before and after exercise measured by echocardiography. (2001) Amino Acids 20(1): 75-82.

9) Bichler, A., Swenson, A., Harris, B.A. A combination of caffeine and taurine has no effect on short term memory but induces changes in heart rate and mean arterial blood pressure. (2006) Amino Acids 31(4): 471476.

10) Ragsdale, F.R., Gronli, T.D., Batool, N., et al. Effect of Red Bull Energy Drink on Cardiovascular and Renal Function. (2010) Amino Acids 38(4): 1193-1200.
11) Alford, C., Cox, H., Wescott, R. The effects of Red Bull drink in human performance and mood. (2001) Amino Acids 21(2): 139-150.

12) Wilson, T., Singh, A.P., Vorsa, N. et al. Human Glycemic Response and Phenolic Content of Unsweetened Cranberry Juice. (2008) J Med Food 11(1): 46-54.

13) Allen, J. The Online Reaction Time Test. (2002).

14) Sullivan, M.J., Scott, R.L. Postprandial glycemic response to orange juice and non-diet cola: is there a difference? (1991) Diabetes Educ 17(4): 274-278.

15) O'Gorman, R.L., Mehta, M.A., Asherson, P., et al. Increased cerebral perfusion in adult attention deficit hyperactivity disorder is normalised by stimulant treatment: a non-invasive MRI pilot study. (2008) Neuroimage 42(1): 36-41.

16) Maughan, R.J., Griffin, J. Caffeine ingestion and fluid balance: a review. (2003) J Hum Nutr Diet 16(6): 411-420.

17) Passmore, A.P., Kondowe, G.B., Johnston, G.D. Renal and cardiovascular effects of caffeine: a dose response study. (1987) Clin Sci 72(6): 749-756.

18) Fenton, R.A., Poulsen, S.B., de, la, Mora, Chavez, S., et al. Caffeine-induced diuresis and natriuresis is independent of renal tubular NHE3. (2015) Am J Physiol Renal Physiol 308(12): F1409-1420.

19) Lovallo, W.R., Pincomb, G.A., Sung, B.H., et al. Caffeine may potentiate adrenocortical stress response in hypertension-prone men. (1989) Hypertension 14(20): 170-176.

20) Energy drink sales hindered by Thai decline. (2009) Just Drinks.
Online ISSN: 2377-0619

Journal Title: International Journal Food and Nutritional Science Journal Short Name: Int J Food Nutr Sci
Ommega Online Publishers

E-mail: foodscience@ommegaonline.org

Website: www.ommegaonline.org 